\title{
Efficacy of Intravaginal Progesterone Sponge in Estrus Induction and Fertility Rate in Indigenous Kangayam Cows under Field Conditions
}

\author{
K. Devipriya ${ }^{1 *}$, P. Selvaraj ${ }^{1}$, S. Jayachandran ${ }^{1}$, K. Balasundaram ${ }^{1}$, \\ K. Sivakumar ${ }^{1}$ and S. Manokaran ${ }^{2}$ \\ ${ }^{I}$ Department of Veterinary Physiology, Veterinary College and Research Institute, \\ Namakkal, India \\ ${ }^{2}$ Kangayam Cattle Research Station, Sathyamangalam, and Erode, Tamilnadu \\ Veterinary and Animal Sciences University (TANUVAS), India \\ *Corresponding author
}

\section{A B S T R A C T}

\section{Keywords}

Kangayam, Jersey cross, Progesterone sponge and conception rate

\section{Article Info}

\section{Accepted:}

20 July 2020

Available Online:

10 August 2020

\begin{abstract}
The effectiveness of progesterone sponges to treat the anestrus animals and to synchronisation was reported in several previous study using different breeds of cattle and buffalo. The present study was carried out to assess estrus induction potential and conception rate in indigenous Kangayam cows inserted with progesterone impregnated intravaginal sponge. About 10 cows were selected after gynaecological examination and the locally prepared intravaginal progesterone sponges were placed in vagina for 9 days and removed on $10^{\text {th }}$ day. Similarly 10 Jersey cows were selected for the study as control. All the cows were noticed carefully for another 2 to 4 days. The estrus score was calculated based on expressed estrus signs. Sponge retention was $100 \%$ in both breeds. Also long duration of hours were taken to induce estrum in Kangayam $(62 \pm 6.95)$ than Jersey cows $(38 \pm 5.66)$ but available time of estrus signs very low in Kangayam $(18 \pm 0.26$ hrs) than Jersey cows ( $24 \pm 0.42 \mathrm{hrs})$. The conception rate in Kangayam breed was $77.78 \%$ and $62.5 \%$ in crossbred Jersey cows. This study concluded that Kangayam cows were taken longer duration to induce estrum and good conception rate.
\end{abstract}

\section{Introduction}

Kangayam, is one of the popular draught purpose indigenous cattle breed of Tamil Nadu. The indigenous cattle breeds were naturally resistant to heat stress however, due to changing climatic condition leads to reproductive failure and irregular hormonal secretions reported in previous studies. Lack of integration or synchronization and endocrine imbalances at any phase of the sequence may result in reproductive failure. In indian subcontinent, the incidence of true anoestrus in cattle $48 \%$ and in buffalo $74 \%$ seen in reared in rural area. The prolonged calving to conception rate in bovine due to various factors, such as breed, parity, season, presence of bull, negative energy balance and suckling. The anestrum and repeat breeding and failure in induction of regular estrus cycle 
and long inter calving interval and feed cost make economic loss to the owner. Estrus detection as a major problem in dairy industry for effective breeding programme (Senthilkumar and Chandrahasan, 2015).

The effects of synchronization treatments on expression of estrus are very important in designing strategies for controlled breeding programme (Quezada-Casasola et al., 2015). In cows the progesterone sponges are equally successful to that of CIDR. (Martinez et al., 2011) reported $60.6 \%$ and $62.9 \%$ conception rate in beef heifers with use of CIDR and MAP sponge respectively. The use of progesterone impregnated vaginal sponges is more practical method of administration. The effectiveness of progesterone sponges were reported in several previous study using different breeds of cattle and buffaloe. However, no reports are available for using the progesterone sponge in Kangayam breed of cattle. The present study was carried out to find out the efficacy of progesterone treated intravaginal sponge in indigenous Kangayam cows on etrus induction and conception response under field conditions.

\section{Materials and Methods}

\section{Study Design}

Ten lactating Kangayam and cross bred Jersey cows between 4-7 years of age were chosen in this study. The animals were spread over different districts Erode, Karur and Namakkal districts of Tamil Nadu state. Out of 25 animals were screened to identify the true anestrus animal for progesterone treatment.

\section{Pre clinical examination}

The animals were thoroughly examined per rectum to conform the anestrous condition by rectal examination, the cow with smooth ovaries with no palpable structure, and not shown estrus signs for 3 to 4 months after calving were included in the study. Some animals were reported to be repeat breeder even timely insemination. All animals were on grazing and stall fed conditions. The progesterone sponges were prepared in Department of Veterinary Physiology, Namakkal.

\section{Administration of progesterone sponge}

The animals were restrained properly. Before insertion of sponge perineum was cleaned with cotton soaked with water in order to remove the dung and other dust particles from the vulval lips. Properly lubricated vaginal speculum with liquid paraffin was inserted through vulva into vagina slowly and gently without any damage to the genital tract. The sponges were inserted inside the speculum and with the help of plastic plunger the sponge was lodged inside the anterior vagina. The progesterone sponge was removed after 9 days of insertion. The onset and frequency of estrus signs were observed and recorded in the estrus symptom recording chart (Mangal, 2009).

\section{Confirmation of pregnancy}

The estrus induction time of each animal was recorded in order to calculate the mean induction time. Those animals in estrus were artificially inseminated with frozen semen. The animals were underwent rectal examination 60 days post insemination to confirm the pregnancy.

Scoring system developed by Dash, (1980) for the Zebu cattle were used for scoring of estrus signs in this study. Estrus expression ranking (maximum score being 100) was done based on cardinal sign (standing heat, mucous discharge, vulvar swelling, micturition, restlessness, bellowing sound, 
mounting, redness of vaginal mucosa, sniffing, chin resting and aggression. The score obtained for each behavioural signs of individual animals were added to obtain a total score (Shahid et al., 2019). All numerical data was analysed statistically.

\section{Results and Discussion}

At the time of sponge removal $100 \%$ progesterone sponge retention $(n=10)$ without any abnormal discharge was observed in all treated animals. This finding is corrlate with several previous studies. Saini et al., (2016) who reported $100 \%$ retention of sponges in anoestrus buffaloes treated with progesterone sponge to induction of estrous cycle. Similarly the locally prepared sponges produced $100 \%$ retention as reported by previous studies carried out in our university (Visha et al., 2014 and Jayachandran et al., 2015).

Kausar et al., (2013) reported that estrus induction using Methyacetoxy progeterone (MAP) sponge for 16 days in cyclic and acyclic buffaloes induced $75 \%$ and $50 \%$ respectively. Similarly MAP for 7 days with PGF $2 \alpha$ exhibits $90 \%$ and $70 \%$ estrus induction in cyclic and acyclic buffaloe. During the day of sponge removal MAP sponges given $75 \%$ and $50 \%$ respectively. Ourresults corroborate with previous studies and it was $90 \%$ (Kangayam) and Jersey cross $(80 \%)$ when used progesterone sponge without PGF2 $\alpha$. Saini et al., (2016) reported $100 \%$ etrus induction in true anestrus buffaloes treated with locally prepared progesterone sponge for 8 days. They administrated 400 IU of PMSG during the day of sponge removal.

The mean hour's duration for estrus induction was $62 \pm 6.95$ in Kangayam and $38 \pm 5.66$ cross bred Jersey cow. Whereas 46 - 49 h for estrus induction in indigenous cattle of Jummu and Kasmir while treated with ovisynch protocol (day 0-GnRH-1, day- 7 PG, and day-9- GnRH- 2) (Shahid et al., (2019). Between Kangayam and Jersey breeds the occurrence of duration of estrus was shorter $(13 \pm 0.26)$ than cross bred Jersey cow (16 \pm 0.42). Estrus duration recorded in present study is in corroborating with other earlier studies (Layek et al., 2011). The authors reported that $14.53 \pm 0.80 \mathrm{~h}$ in Sahiwal cows during natural estrus induction. However, short hours of overall standing heat was observed in high producing HF heifer was 6.4 \pm 4.3 and in adult cow $6.2 \pm 3.9$ (Yoshidha, $\mathrm{C}$ and Nakao. 2005) (Table 1 and 2).

Table.1 Mean sponge retention and estrus induction rate, duration to induction of estrus, duration of estrum and conception rate in anoestrus Kangayam and Jersey cross bred cow treated with Progesterone sponge

\begin{tabular}{|l|c|c|c|c|c|}
\hline \multicolumn{1}{|c|}{ Breed } & $\begin{array}{c}\text { Sponge retention } \\
\text { Rate }(\boldsymbol{\%})\end{array}$ & $\begin{array}{c}\text { Estrus } \\
\text { induction Rate } \\
(\boldsymbol{\%})\end{array}$ & $\begin{array}{c}\text { Time duration to } \\
\text { estrus induction } \\
(\text { Hours) }\end{array}$ & $\begin{array}{c}\text { Occurrence } \\
\text { of estrus } \\
(\mathbf{H o u r})\end{array}$ & $\begin{array}{c}\text { Conception } \\
\text { rate } \\
(\%)\end{array}$ \\
\hline $\begin{array}{l}\text { Group I } \\
\text { (Indigenous Kangayam) }\end{array}$ & 100 & 90 & $62 \pm 6.95^{\mathrm{a}}$ & $18 \pm 0.26$ & $77.78(7 / 9)$ \\
\hline $\begin{array}{l}\text { Group II } \\
\text { (Cross bred Jersey) }\end{array}$ & 100 & 80 & $38 \pm 5.66^{\mathrm{b}}$ & $24 \pm 0.42$ & $62.5(5 / 8)$ \\
\hline
\end{tabular}

The values with different superscript are significantly different between different rows 
Table.2 Different estrus signs and total estrus intensity (Mean \pm SEM) core observed between anoestrus Kangayam and Jersey cross bred cow treated with intravaginal progesterone sponge

\begin{tabular}{|c|c|c|c|c|c|c|c|c|c|c|c|}
\hline $\begin{array}{l}\text { Estrus } \\
\text { observation/ } \\
\text { signs with } \\
\text { number }\end{array}$ & $\begin{array}{l}\text { Standing } \\
\text { Heat } \\
\qquad \text { (25) }\end{array}$ & $\begin{array}{c}\text { Mucus } \\
\text { discharge } \\
(20)\end{array}$ & $\begin{array}{c}\text { Vulvar } \\
\text { swelling } \\
(9)\end{array}$ & $\begin{array}{c}\text { Micturition } \\
\text { (9) }\end{array}$ & $\begin{array}{c}\text { Restlessness } \\
\text { (9) }\end{array}$ & $\begin{array}{c}\text { Bellowing } \\
\text { (6) }\end{array}$ & $\begin{array}{c}\text { Mounting } \\
\text { (6) }\end{array}$ & $\begin{array}{c}\text { Redness of } \\
\text { Vaginal } \\
\text { mucosa } \\
(6)\end{array}$ & $\begin{array}{c}\text { Sniffing } \\
\text { (4) }\end{array}$ & $\begin{array}{c}\text { Aggression } \\
\text { (6) }\end{array}$ & $\begin{array}{l}\text { Total } \\
\text { intensity } \\
\text { score } \\
(100)\end{array}$ \\
\hline $\begin{array}{l}\text { Indigenous } \\
\text { Kangayam }\end{array}$ & $15.5 \pm 1.30$ & $13.2 \pm 0.78$ & $3.8 \pm 0.56$ & $2 \pm 0.33$ & $5.05 \pm 0.49$ & $0.65 \pm 1.80$ & $0.85 \pm 0.39$ & $2.4 \pm 0.39$ & $1.7 \pm 0.48$ & $3.75 \pm 0.48$ & $48.9 \pm 7.0$ \\
\hline $\begin{array}{l}\text { Cross bred } \\
\text { Jersey }\end{array}$ & $20.1 \pm 2.38$ & $18.6 \pm 2.63$ & $7.45 \pm 2.09$ & $7.6 \pm 2.63$ & $4.95 \pm 0.40$ & $4.5 \pm 2.17$ & $3.9 \pm 0.89$ & $4.15 \pm 0.47$ & $2.35 \pm 0.57$ & $4.3 \pm 1.08$ & $\begin{array}{l}77.9 \pm \\
15.31\end{array}$ \\
\hline
\end{tabular}


The present study observed conception rate was $78.78 \%$ in Kangayam cows whereas 62.5 per cent in cross bred Jersey cows. Whereas Honparkhe et al., (2008) reported 60\% and $62.5 \%$ of conception in cattle and buffaloe respectively when Hydroxy progesterone caproate $(750 \mathrm{mg}$ ) used intramuscularly at 72 hrs interval to induce estrum. In another study reported that very low level of conception rate obtained when norgestomate (SynchromateB) ear implants used for 9 days in crossbred cows (Selvaraju, et al., 2011). Another study reported that $84.61 \%$ of conception rate was achieved by use of progesterone injection $(250 \mathrm{mg}$ ) on day 1 and primed with GnRH on day $10^{\text {th }}$ in local anestrus cows (Pawar et al., 2013). Low conception rate as obtained in acyclic buffaloe treated with MAP sponges intravaginally for 16 days (Kausar, et al., 2013). High conception rate in the present study showed that the comparatively high efficacy of locally prepared progesterone sponge and good response from indigenous cows.

The effect of induced estrus on different estrus intensity scores in indigenous Kangayam and cross bred Jersey cows were presented in Table 2. In the present study compared with Kangayam cows, the score intensities were higher in cross bred Jersey cows while compared with lower the findings. Shahid et al., (2019) reported that estrus intensity score in heifer and cow induced with Ovisynch protocol (GnRH with $\mathrm{PG}$ ) group had $50.80 \pm 2.82$ and $51.94 \pm 2.37$ respectively whereas natural estrus induction had $59.67 \pm 5.8$ and $54.83 \pm 4.4$ respectively. They explained that the longer duration of standing heat in synchronized sahiwal heifer might be due to use of exogenous GnRH that inturn increased follicular growth and released higher concentration of estrogen hormone that induce estrus signs more prominent. Similarly in the present study higher duration of induction of estrum and low estrus intensity score in Kangayam cows could be due to delay in release of GnRH and low concentration of estrogen hormone in plasma to express estrus behaviour. The reduction in estrus behaviour involves reduced mounting activity and shorter periods of estrus which limits the use of AI.

Results of present study revealed that use of progesterone impregnated sponges improved conception rate in indigenous Kangayam and jersey cross bred cows. Indigenous Kangayam took long duration to exhibit the estrus signs but the duration of standing heat (estrum) was shorter with good conception rate than Jersey cross bred cows.

The study concluded that use of intravaginal progesterone sponge have better efficacy to improve in synchronization of estrous cycle in cyclic and acyclic Kangayam cows to improve fertility and reduce inter calving interval.

\section{References}

Dash, P.C., 1980. Reproductive behaviour of dairy cows (Bos indicus, Bos taurus and Bos taurus $\times$ Bos indicus). Ph.D. Thesis. (NDRI) Panjab University Chandigarh

Honparkhe, M., Singh, J., Dadarwal, D., Dhaliwal, G.S. and Kumar, J. (2008). Estrus induction and fertility rates in response to exogenous hormonal administration in postpartum anestrus and subestrus bovines and Buffaloes. J.Vet. Med. Sci. 70 (12): 1327-1331.

Jayachandran, S. and Muralidharan, J. (2015). Estrus Induction and Conception Percentage in Anestrus Buffaloes treated with Progesterone. Shanlax International Journal of Veterinary Science. 3(1): 1219.

Kausar, R., Khanum, S. A., Hussain, M., Hussain, T., Ahmad, N., Ahmad, L., and Qureshi, N. A. (2013). Estrus 
synchronization and conception rates using locally prepared methylacetoxy progesterone sponges in cyclic and acyclic Nili-Ravi buffaloes (Bubalus bubalis). Pak Vet J, 33, 433-437.

Layek, S. S., Mohanty, T. K., Kumaresan, A., Behera, K., and Chand, S. (2011). Behavioural signs of estrus and their relationship to time of ovulation in Zebu (Sahiwal) cattle. Animal reproduction science, 129 (3-4), 140-145.

Mangal, V. (2009). Study on Estrous Behaviour, Cervical Mucus Characteristics and Fertility in Sahiwal Cattle. M.V.Sc. Thesis, NDRI, Karnal, Haryana, India.

Martinez MF, G de Nava, KJ emmers, D Tutt, MR Sabarros, B Smaill, M Corti and J Juengel. (2011). Intravaginal progesterone devices in synchroniation protocols for artificial insemination in beef heifers. Reprod Domes Anim, 47: 230-237.

Pawar, S. A., Markandeya, N.M., Sawale, A.G and Kasbe (2012). Studies on induction of oestrus in local anestrus cows with progesterone PRIMED GnRH and Progesterone treatment. Indian Journal of Animal Reproduction 33 (2): 84-86.

Quezada-Casasola, A., L. Avendano- Reyes, U. Macias-Cruz, J.A. Ramirez-Goine, and R.R. Rivas- Caceres (2015). Estrous behaviour, ovulatory follicle dynamics, and corpus luteum size in Creole cows after spontaneous or prostaglandin F2 $\alpha$ induced estrous. Rev. Colom. Cienc.
Pecua. 28(4): 303-312.

Saini, A., Luthra, R. A., Pandey, A.K., Nanda, T. and Kumar, L (2016). Use of progesterone impregnated indigenous sponges along with PMSG for the induction of cyclicity in anestrus Murrah Buffalo. Indian Journal of Animal Reproduction 38 (1):12-15.

Selvaraju, M., Veerapandian, C., Kathiresan, D and Chandrahasan, C. (2011). Induce Oetrus and Progesterone profile in repeat breeder's cows. TamilNadu J. Veterinary and Animal Sciences 7 (5):221-224

Senthilkumar,K and Chandrahasan (2015). Estrus behaviour in natural and induced estrus in dairy cattle by PGF2 $\alpha$ with GnRH and HCG. Int.J.Sci.Environ and Tech. 4(1): 243-247.

Shahid, B., Khan, M. I., Andrabi, S. M. H., Razzaq, A., and Khan, M. N. (2019). Estrus duration and expression in natural and induced estrus in indigenous (Bos indicus) Cattle. JAPS, Journal of Animal and Plant Sciences, 29(3), 645-649.

Visha, P., Jayachandran, S., Nanjappan, K. and palanisammi, A. (2014). Follicular growth pattern in buffaloes synchronized to estrus with progesterone impregnated intravaginal sponges. Int. J. Environ. Sci. TE., 3(3): 960-965.

Yoshida, C. and Nakao, T. (2005). Some characteristics of primary and secondary oestrus signs in high producing dairy cows. Reprod. Domes. Anim.40: 150155.

\section{How to cite this article:}

Devipriya, K., P. Selvaraj, S. Jayachandran, K. Balasundaram, K. Sivakumar and Manokaran, S. 2020. Efficacy of Intravaginal Progesterone Sponge in Estrus Induction and Fertility Rate in Indigenous Kangayam Cows under Field Conditions. Int.J.Curr.Microbiol.App.Sci. 9(08): 2051-2056. doi: https://doi.org/10.20546/ijcmas.2020.908.232 